\title{
Proposição e validação de um modelo de inteligência competitiva específico para Instituições de Ensino Superior (IES) privadas
}

Cassiane Barbosa da Silva

PUC Minas (Núcleo de Pesquisa e Informação da Secretaria de Planejamento e Desenvolvimento Institucional/ Coordenadora).

Professora da FPL Educacional-Professora da Nova Faculdade

Frederico Cesar Mafra Pereira

Professor do Mestrado Profissional em Administração da FPL Educacional (Fundação Pedro Leopoldo-MG

Rodrigo Baroni de Carvalho

Programa de Pós-Graduação em Administração da PUCMinas

Ricardo Vinícius Dias Jordão
Professor do Mestrado Profissional em Administração da FPL Educacional (Fundação Pedro Leopoldo-MG). Doutor em Ciência da Informação (ECI-UFMG)

http://dx.doi.org/10.1590/1981-5344/3002

O trabalho teve como objetivos analisar práticas e ferramentas utilizadas pelas Instituições de Ensino Superior (IES) privadas de Minas Gerais para monitorarem seu ambiente competitivo, e propor e validar um modelo de Inteligência Competitiva (IC) para este segmento. $O$ estudo foi de natureza descritiva e preditiva, via aplicação de formulário eletrônico disponibilizado a todas as IES privadas mineiras, cadastradas no eMec/INEP em 2015. O público-alvo foram os gestores das IES privadas pertencentes à alta administração e à 
coordenação de cursos, no total de 40 gestores de 27 diferentes IES. Os resultados apontaram diferentes percepções entre os entrevistados quanto ao uso de práticas e ferramentas de $I C$, sendo que os conceitos e práticas parecem mais difundidos na perspectiva dos gestores da alta administração. $O$ modelo proposto contemplou as etapas do Ciclo de IC em seus construtos e foi validado por meio da Modelagem de Equações Estruturais. Concluiu-se que as práticas e ferramentas de monitoramento estão presentes nas IES mineiras em um nível informal e desestruturado. Fontes de informações como dados da concorrência e Governo não constaram como as mais monitoradas. A maioria das instituições pesquisadas não apresenta uma área específica de IC, apesar do ótimo nível de conhecimento sobre o conceito.

Palavras-chave: Inteligência Competitiva. Estratégia Competitiva. Instituições de Ensino Superior Privadas. Modelo de IC para IES.

\section{Proposal and validation of a specific competitive intelligence model to private higher education institutions}

This paper aimed to examine what practices and tools used by private higher education institutions of Minas Gerais state, to monitor its competitive environment, and develop and validate a model of Competitive Intelligence (CI) for this segment. The study was descriptive and predictive nature with the application of electronic form available to all private institutions of the state registered on the Ministry of Education in 2015. The audience were managers of these private institutions (belonging to senior management and the coordination of courses), comprising 40 education managers from 27 different institutions. The results showed different perceptions among the public interviewed on the use of practices and CI tools, and the concepts and practices seemed more widespread among top management. The proposed model included the steps of the CI cycle in their constructs and was validated by Structural Equation Modeling (SEM). It was concluded that the CI practices and monitoring tools occurred in an informal and unstructured level. Information sources on competition and government did 
not figure as the most monitored. Most institutions surveyed doesn 't have a specific CI area, despite showing great level of knowledge about the concept.

Keywords: Competitive Intelligence. Competitive Strategy. Private Higher Education Institutions CI for Education Sector.

Recebido em 16.11.2016 Aceito em 06.04.2018

\section{Introdução}

Para se manterem competitivas, as organizações precisam acompanhar os sinais do mercado em que atuam, em alguns momentos claros e definidos, e em outros nebulosos e confusos. Também se tornam necessárias outras funções como: avaliar a relevância e a veracidade das informações e filtrar o que efetivamente afeta a consecução dos objetivos estratégicos da organização à qual representam (COLAUTO; GONÇALVES; MADEIRA, 2006; FULD, 2007; CARVALHO; CASAGRANDE, 2011; VIDIGAL; NASSIF, 2012). É nesse contexto que a Inteligência Competitiva (IC) se torna ainda mais relevante, pois representa um método aplicado que contempla a coleta, análise e difusão de informações por meio do uso de ferramentas e processos, conforme acentuam Bogers, Chesbrough e Moedas (2017) e Cano-Kollmann et al. (2018). A IC permite, dentre outras coisas, o monitoramento do ambiente de negócios de maneira sistematizada, produzindo informações, análises e conhecimentos para alimentar a estratégia organizacional, suportar os processos de tomada de decisão e contribuir para a busca de vantagens competitivas para a empresa frente aos concorrentes (HERRING, 1999; TARAPANOFF, 2001; GOMES; BRAGA, 2001; CARDOSO JR., 2005; MACEDO; RODRIGUES, 2012; MAFRA PEREIRA; SANTOS, 2015; MAFRA PEREIRA; BORGES; JORDÃO, 2015; MAFRA PEREIRA; CARVALHO; JORDÃO, 2016; BOGERS; CHESBROUGH; MOEDAS, 2017).

Esse ambiente competitivo também se faz presente no contexto das Instituições de Educação Superior (IES) privadas. Este mercado no Brasil se expandiu principalmente após a Lei de Diretrizes e Bases (LDB) no 9.394, de 1996 (BRASIL, 1996), a qual trouxe a necessidade de que as IES aumentassem seu nível de profissionalização na gestão e que mudassem seu posicionamento no mercado (CARVALHO; CASAGRANDE, 2011). As IES privadas perceberam a necessidade de um mecanismo gerencial que representasse ferramental capaz de apoiar e suportar suas estratégias, uma vez que o número de concorrentes aumentou e as organizações do setor se fortaleceram em termos estratégicos e gerenciais (COLAUTO; GONÇALVES; MADEIRA, 2006). Segundo o INEP, em 2015, 192 IES privadas atuavam no mercado educacional de Minas Gerais (BRASIL, 2015). 
A literatura sobre IC aborda modelos teóricos conceituais amplos, divididos em etapas. De modo geral, os modelos apresentam similaridades em suas etapas principais, mas não detalham as variáveis necessárias a serem trabalhadas em cada uma, o que dificulta seu uso na prática. Deste modo, os objetivos deste trabalho foram de analisar as práticas e ferramentas utilizadas pelas IES privadas mineiras para monitorarem seu ambiente competitivo e, a partir desta análise, propor e validar um modelo de IC aplicável a este segmento. A justificativa de uma pesquisa advém das contribuições porporcionadas pela mesma como assentam Jordão e Novas (2013) e Jordão, Souza e Avelar. (2014). Para Fuld (2007), a criação de modelos de inteligência permite a elaboração de ferramentas capazes de extrair e reunir informações de maior utilidade vindas de diferentes fontes.

De forma mais específica, acredita-se que a contribuição teóricoempírica deste trabalho é relevante para a Ciência da Informação e a Administração, e para os estudos sobre IC, não somente pela proposição de um modelo voltado ao segmento de IES, mas também pela sua instrumentalização e aplicabilidade. Tal contribuição também permitirá às IES refletirem sobre suas práticas e a aplicação do modelo para subsidiar a estratégia, suportar a tomada de decisão e favorecer na definição de vantagens competitivas frente aos concorrentes.

Além desta introdução, o artigo está estruturado em mais quatro seções. Na segunda seção, é apresentado o referencial teórico, abordando a temática da IC, discutindo o modelo de inteligência empresarial para IES (CARDOSO JR., 2005) e propondo um modelo conceitual de IC para IES. A terceira seção trata dos procedimentos metodológicos adotados. Os resultados são demonstrados e discutidos na quarta seção. A quinta seção contempla as conclusões e faz sugestões para futuros estudos.

\section{Referencial teórico}

O contexto atual exige das organizações competência para recuperar, tratar, interpretar e utilizar a informação sobre o mercado em prol de seus negócios (RODRIGUES; RICCARDI, 2007; VIDIGAL; NASSIF, 2012). A informação resultante desse processo torna-se, portanto, estratégica. A inteligência é a informação que permite ao administrador tomar decisões com maior segurança e previsibilidade quanto aos impactos organizacionais (GOMES; BRAGA, 2001). A respeito da IC, Tarapanoff (2001) afirma que ela exerce a função de uma nova síntese teórica para o tratamento da informação sobre a ambiência e que, se sistematizada e analisada, é usada na tomada de decisão. Esse monitoramento deve envolver competidores, usuários, fornecedores e outras forças industriais, integrando-as ao processo estratégico da organização.

\subsection{Inteligência competitiva}


Para Gomes e Braga (2001, p. 28), a IC é entendida como "o resultado da análise de dados e informações coletadas do ambiente competitivo da empresa que irão embasar a tomada de decisão, pois gera recomendações que consideram eventos futuros e não somente relatórios para justificar decisões passadas". Tarapanoff (2001, p. 45) argumenta que: "adicionalmente à coleta de dados factuais, a IC também envolve a habilidade de desenvolver o entendimento das estratégias e da forma de agir de seus competidores". Para acompanhar os objetivos dos concorrentes e as imprevisibilidades do mercado, é recomendado que sejam usados registros públicos, Internet e comunicação de massa, relacionamento com stakeholders e especialistas do setor.

Rodrigues e Riccardi (2007) opinam que a IC deve representar um sistema organizacional inteligente, um conjunto maior composto por arquitetura de Tecnologia da Informação (TI) e a construção das bases cognitivas internas, sendo que seu objetivo último é desenvolver competências essenciais na organização, que, por consequência, gera o conhecimento especializado que é capaz de produzir soluções inovadoras e criativas.

Ao longo do tempo, as empresas vêm se esforçando e aprimorando práticas, ferramentas e técnicas de Inteligência nas áreas de Marketing e Planejamento Estratégico para o monitoramento e análise ambiental (PRESCOTT; MILLER, 2002). Importante frisar que Tyson (1990) já definia IC como a disciplina capaz de integrar o planejamento estratégico e as atividades de marketing e de informação, objetivando o monitoramento constante do ambiente externo, com respostas rápidas e precisas à empresa, no que diz respeito aos movimentos de mercado. Neste ponto, há que se ressaltar o aspecto multidisciplinar do campo da IC.

Fuld (2007, p. 3-14) considera a IC como a "informação analisada que fornece insights e Vantagem Competitiva [...] significa ver por completo e à frente do mais rápido concorrente. Seu principal objetivo é a melhoria da posição de mercado da empresa e de seus resultados mais críticos". Segundo Lodi (2005), o papel da IC vai além de monitorar os movimentos dos concorrentes, seus recursos e capacidades em comparação com a empresa. A IC monitora o ambiente competitivo em sua totalidade, com o intuito de prever mudanças no macroambiente (política, economia, sociedade, tecnologia e legislação) e no mercado ou indústria (consumidores, concorrentes, fusões e aquisições e inovações).

Para Miller (2002) e Bernhardt (2004), os processos da IC podem ser estruturados e compreendidos por meio do modelo denominado 'Ciclo de Inteligência'. A literatura sobre IC apresenta modelos, processos e sistemas, constituídos por etapas, como mostra o Quadro 1:

Quadro 1 - Modelos e etapas do Ciclo de Inteligência

\begin{tabular}{l|l|l|l|l|l|l}
\hline \multirow{2}{*}{ Autores } & \multicolumn{5}{|c}{ Etapas básicas } \\
\cline { 2 - 7 } & Planejamento & Coleta & $\begin{array}{l}\text { Tratamento e } \\
\text { processamento }\end{array}$ & Análise & Disseminação & $\begin{array}{l}\text { Uso e } \\
\text { avaliação }\end{array}$ \\
\hline \hline $\begin{array}{l}\text { Herring } \\
(1999)\end{array}$ & $\begin{array}{l}\text { Planejamento e } \\
\text { identificação das } \\
\text { necessidades de }\end{array}$ & $\begin{array}{l}\text { Planejamento e } \\
\text { armazena- } \\
\text { mento. }\end{array}$ & Coleta & $\begin{array}{l}\text { Análise e } \\
\text { produção }\end{array}$ & $\begin{array}{l}\text { Disseminação } \\
\text { de inteligência } \\
\text { para o decisor }\end{array}$ & \\
\hline
\end{tabular}


Cassiane Barbosa da Silva; Frederico Cesar Mafra Pereira; Rodrigo Baroni de Carvalho; Ricardo Vinícius Dias Jordão

\begin{tabular}{|c|c|c|c|c|c|c|}
\hline & inteligência & & & & & \\
\hline $\begin{array}{l}\text { Gomes e } \\
\text { Braga } \\
(2001)\end{array}$ & $\begin{array}{l}\text { Identificação das } \\
\text { necessidades de } \\
\text { informação }\end{array}$ & $\begin{array}{l}\text { Coleta e } \\
\text { tratamento de } \\
\text { informações }\end{array}$ & & $\begin{array}{l}\text { Análise } \\
\text { final das } \\
\text { informa- } \\
\text { ções }\end{array}$ & Disseminação & $\begin{array}{l}\text { Avalia- } \\
\text { ção }\end{array}$ \\
\hline $\begin{array}{l}\text { Prescott e } \\
\text { Miller } \\
\text { (2002) }\end{array}$ & $\begin{array}{l}\text { Planejamento e } \\
\text { condução/ } \\
\text { planejamento e } \\
\text { armazenamento da } \\
\text { informação }\end{array}$ & Coleta & & $\begin{array}{l}\text { Análise e } \\
\text { produção }\end{array}$ & Disseminação & \\
\hline $\begin{array}{l}\text { Cardoso Jr. } \\
(2005)\end{array}$ & $\begin{array}{l}\text { Identificação dos } \\
\text { usuários e } \\
\text { determinação das } \\
\text { suas necessidades }\end{array}$ & $\begin{array}{l}\text { Reunião das } \\
\text { informações }\end{array}$ & $\begin{array}{l}\text { Processamento do } \\
\text { material reunido }\end{array}$ & & $\begin{array}{l}\text { Disseminação } \\
\text { da inteligência } \\
\text { para os usuários }\end{array}$ & \\
\hline Fuld (2007) & $\begin{array}{l}\text { Planejamento e } \\
\text { direção }\end{array}$ & $\begin{array}{l}\text { Coleta de } \\
\text { informações } \\
\text { secundárias } \\
\text { publicadas } \\
\end{array}$ & $\begin{array}{l}\text { Coleta de } \\
\text { informações } \\
\text { primárias }\end{array}$ & $\begin{array}{l}\text { Análise e } \\
\text { produção }\end{array}$ & $\begin{array}{l}\text { Reporte e } \\
\text { informe }\end{array}$ & \\
\hline
\end{tabular}

Fonte: Dados da pesquisa.

Nesse estudo, foi selecionado o modelo de Cardoso Jr. (2005) como marco teórico, por tratar o tema da IC especificamente voltada para o segmento de IES. O uso de modelos setoriais em IC pode ser visto em trabalhos recentes de Mafra Pereira e Santos (2015) (empresas da indústria alimentícia de produtos processados), Mafra Pereira, Borges e Jordão (2015) (Centrais de Negócios) e Mafra Pereira, Carvalho e Jordão (2016) (Arranjos Produtivos Locais).

\subsection{O modelo de inteligência empresarial em IES}

Cardoso Jr. (2005) apresenta o que denomina Inteligência Empresarial (IE), na qual suas funções básicas descrevem a existência de três unidades interativas: unidade de coleta, unidade de análise e unidade de controle, tendo como componentes desse sistema os coletores de informações, os analistas de inteligência e o gestor de inteligência (Figura 1), estrutura defendida por Herring (1999).

Figura 1 - Célula de Inteligência Empresarial e funções básicas

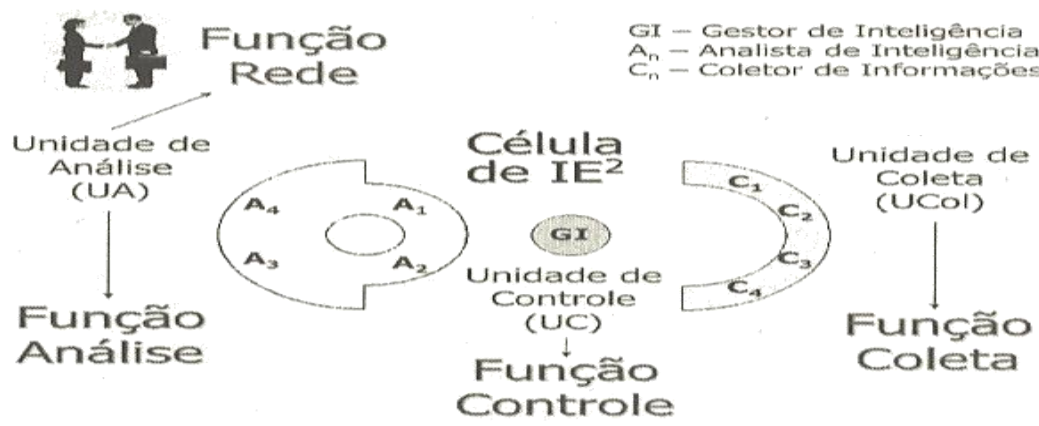

Fonte: CARDOSO JR. (2005).

Sobre a função inteligência na gestão de IES, Cardoso Jr. (2005) destaca a existência de condições excepcionais para seu desenvolvimento, devido a algumas características preexistentes, como: facilidade de acesso à mão de obra qualificada (discentes e docentes); cultura de valorização 
da informação e do conhecimento; facilidade de acesso ao conhecimento e à aprendizagem; níveis desenvolvidos da infraestrutura de telecomunicações dentro da IES; zelo pela ética; operação de campo eficiente; baixa proteção da propriedade intelectual devido à função social de levar o conhecimento a todos; existência de organizações de fomento à pesquisa; facilidade para a estruturação de redes de colaboradores; e o fato de que as IES já são, por sua essência, produtoras de conhecimento.

O modelo elaborado indica que a função inteligência sustentaria três pilares em uma IES privada: uma disciplina regular de IC, um Núcleo de Pesquisa em IC (NIC) e uma Unidade de IC (UIC). Segundo Cardoso Jr. (2005), a disciplina acadêmica teria o objetivo de capacitar os discentes para a prática e para a aplicação da função inteligência no campo da pesquisa e do desenvolvimento (ensino). Já o NIC atuaria a partir da pesquisa, estimulando a inovação do conhecimento e oportunizando a melhoria contínua dos modelos e da formação profissional (pesquisa e extensão). A UIC, por sua vez, representaria uma estrutura independente dos pilares de ensino, pesquisa e desenvolvimento e extensão, sendo totalmente voltada para as atividades empresariais e corporativas de IC, ou seja, uma entidade estratégica da estrutura empresarial.

Baseado no modelo apresentado por Miller (2002), Cardoso Jr. (2005) desenvolveu o que intitulou de metodologia de trabalho interativo do NIC (Figura 2). Essa metodologia trabalha com uma diversidade de fontes de informações, em sua maioria externas, tendo como insumos trabalhos acadêmicos e a prestação de serviços externos. O foco contempla o apoio a decisões estratégicas, alertas antecipados, aprendizagem com atores-chave e a busca de novas tecnologias.

Figura 2 - Metodologia de trabalho interativo do NIC

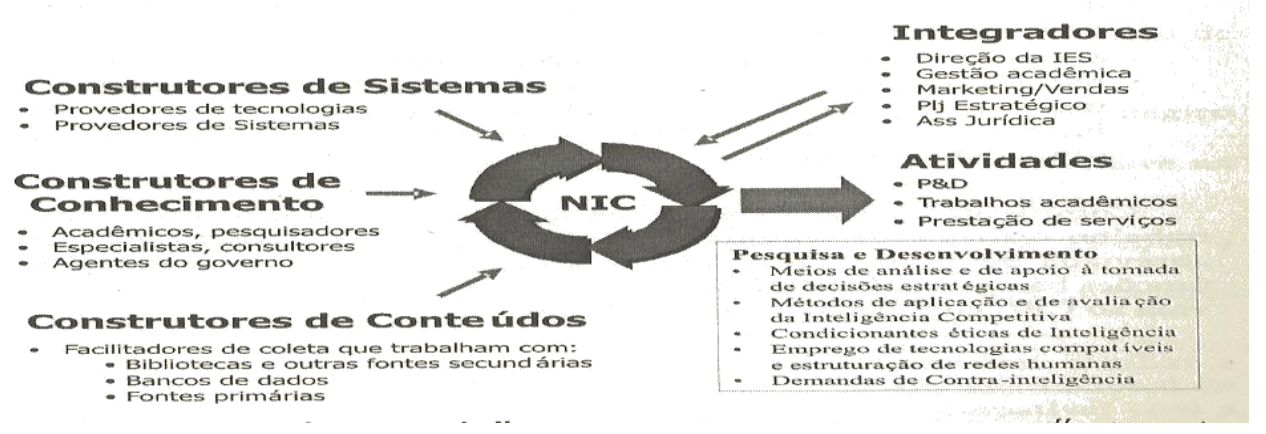

Fonte: CARDOSO JR (2005).

Com a intenção de garantir mais lucratividade e competitividade ao negócio, a UIC deve atuar alinhada à missão institucional da IES, subsidiando a administração estratégica. O CPI (Ciclo de Produção de Inteligência) é um modelo de inteligência proposto por Cardoso Jr. (2005), composto pelas etapas de: i) Planejamento do processo como um todo; ii) Reunião das informações; iii) Processamento do material reunido; e iv) Disseminação da Inteligência para os usuários.

$\mathrm{Na}$ etapa do 'Planejamento do processo como um todo', é feita a identificação dos usuários e a determinação das suas necessidades. $\mathrm{Na} 2^{\mathrm{a}}$ 
etapa, quanto à sua natureza, Cardoso Jr. (2005) classifica a informação como aberta ou fechada. A informação aberta geralmente está disponível de forma escrita e pode ser encontrada de maneira ética e legal e, em sua maioria, já está disponível em grande quantidade na própria organização. Já a fechada é representada pela informação que ainda não se tornou pública e, comumente, circula de forma oral ou está armazenada de maneira sigilosa em alguma memória protegida (digital ou física). Em função da diversidade da informação quanto à natureza, tipo, classe, entre outras divisões, durante a busca pela informação o gestor, na $1^{a}$ etapa do CPI, deverá prever para a $2^{a}$ etapa as seguintes dimensões: 0 ambiente onde a informação necessária localiza-se, as fontes de informação que deverão ser consultadas e os instrumentos e métodos necessários para a coleta de dados (PORTER, 1986; 1989; HERRING, 2002; FULD, 2007; MAFRA PEREIRA; BARBOSA, 2008; MAFRA PEREIRA, 2016).

A $3^{a}$ Etapa do CPI é a atividade do analista de Inteligência. Segundo Cardoso Jr. (2005), este é o principal responsável pelo processamento das informações, e deve obter respostas satisfatórias para cada questão levantada, cabendo a ele fazer os questionamentos adequados. A capacidade de elaborar perguntas que os concorrentes não conseguem propor é competência fundamental.

A $4^{a}$ Etapa deverá observar elementos constantes nas etapas anteriores, como o mapeamento dos públicos que deverão ter acesso, bem como requisitos do tipo periodicidade, pertinência e tempestividade, o nível de sigilo, a melhor forma de apresentação e o melhor meio de envio de cada inteligência gerada.

A função IC foi implementada na UNISUL (Universidade do Sul de Santa Catarina), conforme modelo proposto por Cardoso Jr. (2005). Como contribuições foram relatados trabalhos do tipo: estudo sobre a identificação de professores titulados no mercado regional e nacional, estudo sobre o ambiente externo de educação superior, análise sobre o futuro do mercado de telecomunicações e informática e a relação com curso específico da UNISUL, mapeamento de competidores importantes na região, relatório sobre a situação do mercado de educação superior no Brasil e Santa Catarina e relatórios quinzenais de competitividade com base nas movimentações do mercado de educação superior.

\subsection{Marco teórico e proposição de modelo conceitual}

Visando atender aos objetivos propostos nesse trabalho, optou-se por utilizar como base o modelo de Cardoso Jr. (2005), acrescido de dimensões e variáveis identificadas nos autores referenciados sobre o tema de IC. Dessa forma, o Quadro 2 apresenta o 'Modelo Conceitual Ciclo de Produção de Inteligência Competitiva para IES', que servirá, tanto de estrutura para a avaliação do uso da IC pelas IES mineiras, quanto como modelo a ser validado pelo trabalho. Sobre este modelo, vale destacar que: i) as etapas, conforme referência de Cardoso Jr. (2005), 
Cassiane Barbosa da Silva; Frederico Cesar Mafra Pereira; Rodrigo Baroni de Carvalho; Ricardo Vinícius Dias Jordão

foram consideradas como construtos de $2^{\circ}$ nível; ii) estes constructos são compostos por dimensões, consideradas como constructos de $1^{0}$ nível, e representam os grupos de perguntas do formulário utilizado neste estudo; iii) cada construto de $1^{\circ}$ nível foi composto por variáveis, sugeridas pelos autores desse trabalho, as quais propõem uma avaliação de práticas, ferramentas, instrumentos, métodos e atividades relacionados à IC identificados no referencial teórico.

Quadro 2 - Modelo Conceitual: Ciclo de Produção de IC para IES

\begin{tabular}{|c|c|c|}
\hline $\begin{array}{c}\text { Construto de } 2^{\circ} \\
\text { nível }\end{array}$ & $\begin{array}{c}\text { Construto de } 1^{\circ} \\
\text { nível }\end{array}$ & Variáveis \\
\hline \multirow[t]{2}{*}{ Planejamento } & $\begin{array}{c}\text { Dimensão } \\
\text { planejamento }\end{array}$ & $\begin{array}{l}\bullet \text { Planejamento das atividades de coleta, processamento e distribuição } \\
\text { das informações } \\
\bullet \quad \text { Identificação dos usuários de informação na instituição } \\
\bullet \quad \text { Mapeamento periódico das necessidades informacionais dos usuários } \\
\text { da alta administração } \\
\bullet \quad \text { Mapeamento periódico das necessidades informacionais dos usuários } \\
\text { tomadores de decisão } \\
\text { • Avaliação/mensuração dos resultados das atividades relacionadas à } \\
\text { coleta de informações }\end{array}$ \\
\hline & Dimensão equipe & $\begin{array}{ll}- & \text { Gestor } \\
- & \text { Analista } \\
- & \text { Coletores }\end{array}$ \\
\hline \multirow{3}{*}{$\begin{array}{l}\text { Reunião das } \\
\text { informações }\end{array}$} & $\begin{array}{c}\text { Dimensão } \\
\text { ambiente externo }\end{array}$ & $\begin{array}{ll}- & \text { Informações políticas, regulatórias e leis } \\
- & \text { Informações tecnológicas e inovações } \\
- & \text { Informações socioculturais e demográficas } \\
\bullet & \text { Informações econômicas } \\
\text { - } & \text { Informações do meio ambiente } \\
\end{array}$ \\
\hline & $\begin{array}{l}\text { Dimensão fontes } \\
\text { de informação }\end{array}$ & $\begin{array}{ll}\text { - } & \text { Empresários/executivos da instituição (nível estratégico) } \\
\text { - } & \text { Diretores/gerentes (nível tático) } \\
\text { - } & \text { Demais funcionários (nível operacional) } \\
\text { - } & \text { Empresários/executivos de outras empresas (nível estratégico) } \\
\text { - } & \text { Consuncionários da concorrência } \\
\text { liberais/advogados/publicitários/universidades } \\
\text { - } & \text { Amigos/conhecidos/familiares } \\
\text { - } & \text { Parceiros/fornecedores/distribuidores } \\
- & \text { Funcionários de órgãos públicos e Governo } \\
\text { - } & \text { Órgãos públicos e Governo } \\
- & \text { Clientes (prospects, suspects e atuais) } \\
- & \text { Cliente da concorrência } \\
- & \text { Concorrentes } \\
- & \text { Instituições financeiras } \\
\text { - } & \text { Associações comerciais/empresariais/de classe } \\
\end{array}$ \\
\hline & $\begin{array}{l}\text { Dimensão } \\
\text { métodos/ } \\
\text { instrumentos de } \\
\text { coleta de dados }\end{array}$ & $\begin{array}{ll}\text { - } & \text { Entrevista (s) } \\
- & \text { Pesquisa (s) de mercado } \\
- & \text { Pesquisa (s) interna } \\
\text { - } & \text { Base (s) de dados interna (s) } \\
\text { - } & \text { Base (s) de dados externa (s) } \\
\text { - } & \text { Provedor (es) de notícias } \\
\text { Superior } & \text { Publicações de jornais e revistas especializados no segmento de Ensino } \\
- & \text { Publicações de órgãos públicos e Governo } \\
\text { - } & \text { Sistema de dados informatizado da instituição } \\
- & \text { Sistema de dados informatizado terceirizado } \\
- & \text { Relatórios internos } \\
- & \text { Relatórios externos prontos } \\
- & \text { Ferramentas de Tecnologia da Informação (e-mail, Internet, Intranet, } \\
\text { portal) } & \end{array}$ \\
\hline
\end{tabular}




\begin{tabular}{|c|c|c|}
\hline \multirow[t]{2}{*}{$\begin{array}{l}\text { Processamento do } \\
\text { material coletado }\end{array}$} & $\begin{array}{c}\text { Dimensão } \\
\text { ferramentas de } \\
\text { análise setorial e } \\
\text { do ambiente }\end{array}$ & $\begin{array}{ll} & \text { Análise de cadeia de valor } \\
- & \text { Benchmarking } \\
- & \text { Planejamento de cenários } \\
- & \text { Análise SWOT (Forças, Fraquezas, Oportunidades e Ameaças) } \\
- & \text { Planejamento Estratégico } \\
- & \text { Forças de Porter } \\
\text { - } & \text { Fatores críticos de sucesso } \\
\text { Jogos de Guerra }\end{array}$ \\
\hline & $\begin{array}{c}\text { Dimensão } \\
\text { processamento de } \\
\text { dados }\end{array}$ & 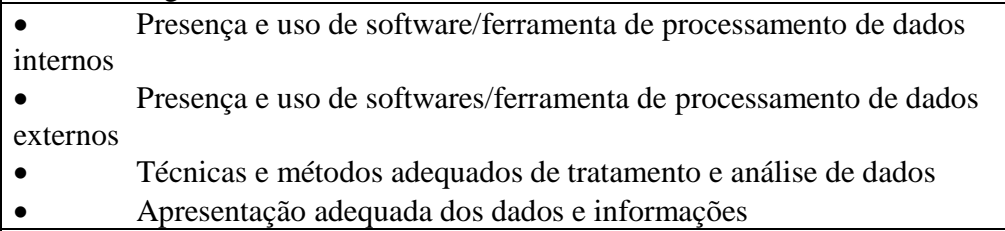 \\
\hline $\begin{array}{c}\text { Difusão da } \\
\text { inteligência para os } \\
\text { usuários }\end{array}$ & & 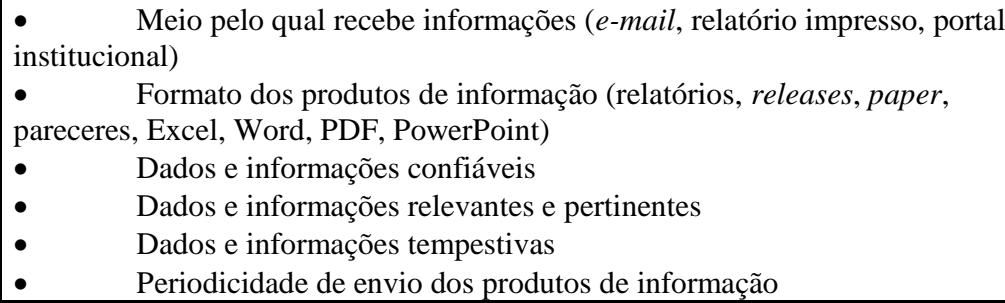 \\
\hline
\end{tabular}

Fonte: Dados da pesquisa.

\section{Procedimentos metodológicos}

Este estudo se caracteriza, quanto aos fins, como uma pesquisa descritiva e preditiva, por meio de abordagem quantitativa via survey de opinião (COLLIS; HUSSEY, 2006; MALHOTRA, 2012). Quanto aos resultados, trata-se de uma pesquisa dedutiva, que se inicia a partir de uma estrutura conceitual e teórica que é testada empiricamente (COLLIS; HUSSEY, 2006). Foi realizada survey quantitativa via formulário semiestruturado e autoaplicável (TRIVINÕS, 1992), desenhada no software SurveyMonkey e disponibilizada a dois profissionais para o préteste com a validação de construtos e conteúdo. Após, o link do formulário foi enviado via e-mail para todas as IES mineiras presentes na base de dados do e-MEC (BRASIL, 2013).

A coleta de dados priorizou a mensuração do nível de conhecimento e estruturação de IC presente nas IES participantes, segundo o Modelo Conceitual: Ciclo de Produção de Inteligência Competitiva para IES (Quadro 2). Foram abordadas todas as IES com unidades em funcionamento no $1^{0}$ semestre de 2015 em Minas Gerais, totalizando o universo de 192 IES, conforme site do e-MEC (BRASIL, 2015). O públicoalvo da pesquisa foi composto por reitor/presidente, pró-reitor/diretor, assessor/gerente, coordenador de curso ou cargos equivalentes em cada estrutura organizacional, em razão destes atores representarem o grupo de informantes-chave do objeto do estudo e em face da necessidade de retratar a opinião dos profissionais que desempenham papel estratégico e gerencial nas instituições participantes (MALHOTRA, 2012). Ao final, o estudo contemplou um total de 32 IES atuantes em Minas Gerais, atingindo 65 entrevistas, das quais 40 foram consideradas válidas a partir do critério de completude dos dados necessários para as análises estatísticas, representando 27 IES. 
A amostra foi do tipo não-probabilística do tipo 'bola de neve' ou 'de rede', característica de estudos fenomenológicos que partem da experiência das pessoas com o assunto estudado (COLLIS; HUSSEY, 2006). Quanto à análise dos dados, primeiramente foi realizado tratamento das respostas para padronização e elaboração de categorias de análise. Em seguida, foram realizadas as análises com base em estatística descritiva, permitindo a apresentação, análise e interpretação de dados numéricos, por meio da criação de quadros, gráficos e indicadores (COLLIS; HUSSEY, 2006). Para a elaboração dos instrumentos de análise descritivos, foi utilizado o software Minitab (versão 17) para acessar e comparar distribuições de amostra e Excel para a elaboração dos gráficos. Na segunda etapa da análise, foi utilizada a modelagem de equações estruturais (MEE) (HAIR et al., 2009), sendo utilizados os softwares SPSS v. 20 e AMOS v. 18. Adicionalmente foi verificada a confiabilidade dos constructos por meio da medida Alpha de Cronbach (MALHOTRA, 2012).

\section{Apresentação e discussão dos resultados}

\subsection{Caracterização da amostra e análise descritiva}

Dentre as IES privadas representadas no estudo, 96,1\% possuem controle privado do capital e apenas 3,9\% são de economia mista. Quanto à organização acadêmica, 58,8\% são faculdades, $21,6 \%$ universidades e $19,6 \%$ centros universitários. Na classificação de categoria administrativa, $100 \%$ são privadas, das quais $42,9 \%$ com fins lucrativos e $12,2 \%$ filantrópicas. As IES sem fins lucrativos (44,9\%) se dividem entre: $28,6 \%$ do tipo confessional, 12,2\% comunitária e 4,1\% especial (BRASIL, 1996, art.20) (FIG.3 e FIG.4).

Figura 3 - Classificação das IES

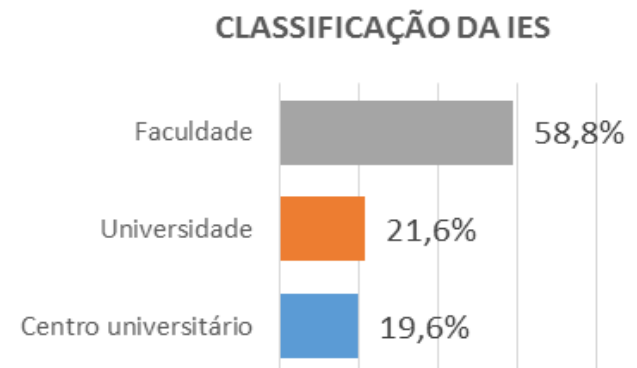

$\begin{array}{lllll}0 \% & 20 \% & 40 \% & 60 \% & 80 \%\end{array}$
Figura 4 - Tipo de IES

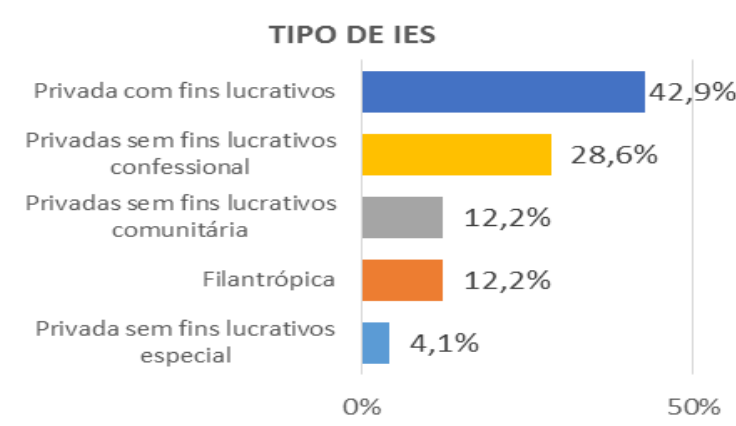

Fonte: Dados da pesquisa.

Fonte: Dados da pesquisa.

Quanto ao cargo dos 40 respondentes, 3,9\% são reitores/presidentes ou possuem cargo equivalente, 23,5\% são próreitores/diretores, 5,9\% assessores/procuradores/gerentes e $66,7 \%$ coordenadores de cursos. Para algumas análises subsequentes, os 
entrevistados foram divididos em dois grupos: alta administração, que contempla as três primeiras categorias citadas, e coordenação. Quanto ao tempo de atuação no cargo, os entrevistados possuem experiência de 4,5 anos considerando a média geral. A alta administração apresenta fatia ligeiramente maior dos representantes com mais de 10 anos de atuação no cargo. Sobre o tempo de atuação na gestão de IES, a média geral é de 8,9 anos. O grupo da alta administração demonstrou maior tempo de experiência na gestão de IES; porém, os dois públicos analisados possuem tempo de experiência no cargo atual por período muito similar, o que sugere bom conhecimento do negócio e da IES representada.

Foi solicitado aos respondentes que avaliassem a postura da IES frente às mudanças do seu ambiente de negócios. No geral, 7,8\% dos respondentes classificaram sua IES como 'Reativa pouco estruturada' (sem objetivos claros e definidos); 37,3\% a classificaram como 'Reativa conservadora e cautelosa'; 23,5\% como 'Proativa pouco estruturada'; e $31,4 \%$ como 'Proativa com visão de futuro' (agindo com base em estudos prospectivos). Quando a avaliação é observada por grupo de respondentes, o grupo da alta administração percebe sua instituição com uma postura ligeiramente mais proativa $(6,1 \%)$ em comparação com a visão da coordenação (Figura 5). O pressuposto para essa diferença de percepção entre os grupos pode estar relacionado ao fato de que os coordenadores, apesar de também estarem envolvidos nas tomadas de decisão das IES, ainda são pouco envolvidos nas estratégias do negócio, o que limita sua visão sobre os fenômenos ligados à competitividade e às respostas da organização frente às mudanças do ambiente.

Sobre o ambiente competitivo atual do segmento de ensino superior, os respondentes avaliaram o nível de instabilidade percebido e a capacidade de previsão de eventos futuros pela IES. Ambas avaliações foram feitas em escala crescente de concordância com 10 pontos. Sobre a instabilidade, na avaliação geral, os entrevistados atribuíram nota 5,4, sendo que os representantes da alta administração leem esse mercado como ligeiramente mais instável $(6,5)$ do que os coordenadores $(4,9)$. No que tange à capacidade de previsão de eventos futuros, a avaliação geral ficou em 5,8 pontos. Mais uma vez o grupo da alta administração apresenta uma visão um pouco diferente do grupo de coordenação: as avaliações foram de 6,4 e 5,4 pontos, respectivamente.

Figura 5 - Postura da IES frente às mudanças do ambiente de negócios

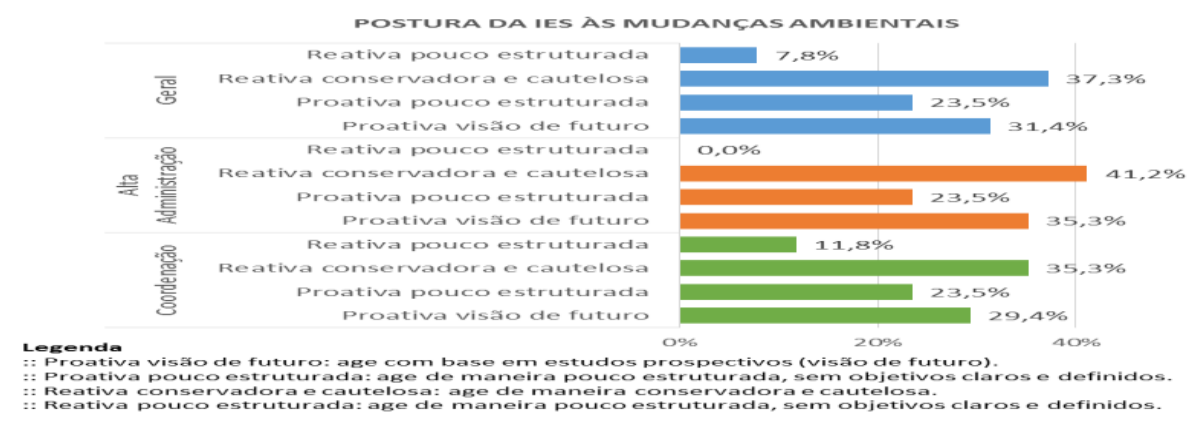

Fonte: Dados da pesquisa. 
Os respondentes também avaliaram a IES com relação ao Planejamento Estratégico (PE). Quanto aos elementos usados para o PE, avaliaram o uso de: experiência, intuição e informação. A experiência mostrou-se como item ligeiramente mais utilizado, à frente da informação (notas 7,5 e 7,4), enquanto à intuição foi atribuída nota 5,8 , no geral. Na alta administração, a informação aparece com um peso ligeiramente maior do que a experiência. No grupo da coordenação, a avaliação é inversa, com a experiência ligeiramente à frente da informação.

Com o objetivo de identificar se as IES mineiras fazem uso de ferramentas e práticas de IC, avaliou-se a ocorrência do CPI, conforme referência de Cardoso Jr. (2005), com foco na validação do 'Modelo Conceitual: Ciclo de Produção de Inteligência Competitiva para IES' proposto, medindo o nível de concordância dos entrevistados com a aplicação de ações relacionadas à informação. As avaliações que envolveram os construtos de $2^{\circ}$ nível foram realizadas a partir de escala crescente de concordância com 10 pontos.

Quanto às afirmativas que representam ações e postura das IES com relação à informação, os enunciados dos itens avaliados foram:

a) 'A minha instituição planeja de maneira estruturada a coleta de informações sobre o ambiente competitivo';

b) 'A captura de informações sobre o ambiente competitivo é realizada de forma constante, por um grupo designado pela instituição';

c) 'A minha instituição utiliza métodos, ferramentas e práticas adequados para a coleta, processamento e análise das informações';

d) 'As informações capturadas e analisadas são distribuídas de forma permanente entre os setores ou áreas'.

Considerando as notas médias, os participantes avaliaram as quatro frases (construtos de $2^{\circ}$ nível) com variação máxima, entre uma e outra, de 0,5 pontos, o que sugere coesão nas ações e postura da IES com relação à informação e proximidade das práticas neste segmento com os pressupostos teóricos de IC. Contudo, observando as respostas de acordo com os grupos de respondentes, a alta administração demonstrou maior grau de concordância com as asserções propostas, em termos de adesão ao modelo, do que o grupo da coordenação.

\subsection{Avaliação das etapas do modelo e suas dimensões}

Na avaliação da dimensão 'Planejamento' da etapa de mesmo nome (vide Quadro 2), os resultados apontam para uma percepção diferente entre os grupos analisados. A coordenação apresenta maior dispersão de notas, com média e mediana tendendo para 6 pts. ou menos, enquanto a alta administração apresenta notas mais homogêneas e com média e mediana tendendo para 7 pts. ou mais. 
Na análise referente à dimensão 'Equipe de Inteligência', buscou-se medir a concordância ou discordância com a presença de cada ocupação executada por mão de obra qualificada considerada necessária ao sucesso de uma área de Inteligência. Os participantes da pesquisa indicaram maior concordância com a presença de profissional qualificado primeiramente para o papel de gestor, seguido do analista e, por último, do coletor. Para as funções de gestor e analista, as notas gerais ficaram em 8 e 7,5, respectivamente, e para o coletor, em 5,7. Nessa mensuração, manteve-se a diferença de aproximadamente 1 ponto entre as avaliações dos grupos. Mais uma vez as avaliações da alta administração apresentaram menor dispersão do que no grupo da coordenação. Já na etapa "Reunião de informações" em sua dimensão 'Ambiente Externo' (Quadro 2), as informações econômicas e as informações políticas, regulatórias e leis foram consideradas como as mais acompanhadas e relevantes para as IES.

$\mathrm{Na}$ avaliação da dimensão 'Fontes de Informação', os públicos do ambiente interno de nível estratégico e tático, seguidos dos clientes da IES, associações, consultores e profissionais liberais, foram indicados como as fontes mais acompanhadas. Neste item, destaca-se o fato de que as fontes ligadas ao Governo (referentes a assuntos como política, regulação, leis e economia) não ficaram entre as mais acompanhadas, contradizendo o construto avaliado anteriormente sobre os ambientes mais acompanhados. Isto aponta para uma falha no que diz respeito às fontes de informação que foram mapeadas e estão sendo usadas para o monitoramento das informações políticas, regulatórias e leis. Outro ponto importante que se apresenta nessa avaliação é com relação à análise da concorrência. Nesta dimensão, as fontes que representam informações sobre a concorrência figuraram entre as piores avaliações.

Em relação à dimensão que trata dos 'Métodos e Instrumentos de Coleta de Dados', as maiores notas se apresentaram para o uso de ferramentas, relatórios, repositórios e dados relativos ao ambiente interno das IES. O uso de ferramentas e de dados externos à organização não são devidamente contemplados. Destaca-se também que, nesse conjunto de variáveis, a maior nota foi atribuída ao uso de ferramentas de TI, elemento da definição da estratégia que, por si só, não representa o exercício pleno da atividade de Inteligência (RODRIGUES; RICCARDI, 2007).

No construto de 20 nível "Processamento do Material Coletado", foram avaliadas as dimensões (construtos de $1^{0}$ nível) referentes às 'Ferramentas de Análise Setorial e do Ambiente' e ao 'Processamento de Dados'. A ferramenta mais utilizada pelas IES é o Planejamento Estratégico. Além desta, a Matriz SWOT, o Benchmarking, as Forças de Porter, os Fatores Críticos de Sucesso e o Planejamento de Cenários também apresentaram fortes indicativos de uso por parte da alta administração das IES. Para o grupo da coordenação, todas as ferramentas obtiveram nota abaixo de 6 pontos na escala de uso. 
Quanto à dimensão 'Processamento de Dados', houve maior concordância por parte do grupo da alta administração quanto à presença e uso dessas variáveis em seus contextos organizacionais do que no grupo de coordenação. Continuando, a presença e uso de software/ferramenta de processamento de dados externos foi a variável com a nota mais baixa, enquanto a presença e uso de software/ferramenta de processamento de dados internos foi a que obteve a maior nota.

No construto referente à etapa "Difusão da Inteligência para os usuários", a tempestividade e a periodicidade foram os únicos elementos avaliados com notas inferiores a 7 pontos pelos entrevistados das IES. Como variável mais bem avaliada, houve destaque para o meio de recebimento dos produtos de informação.

Além da avaliação das variáveis do modelo conceitual proposto, os entrevistados também opinaram quanto à vantagem e ao diferencial competitivo percebido no uso do conjunto de práticas e ferramentas avaliadas. Em sua totalidade, a alta administração reconhece como positivo o uso de tais práticas e ferramentas, visando o atingimento de vantagem/diferencial competitivo às IES. Já para a coordenação, esse reconhecimento é afirmativo para cerca de $70 \%$.

Investigou-se também sobre a presença das áreas de Marketing e IC nas instituições participantes. Para $85,7 \%$ dos respondentes da alta administração, suas IES possuem área de Marketing implementada, e $35,7 \%$ afirmam existir uma área denominada Inteligência Competitiva. Na opinião da coordenação, esses percentuais caem para 83,3\% e 25\%, respectivamente.

A pesquisa avaliou a percepção dos entrevistados quanto à prática de IC pela concorrência. Destaca-se que $7,1 \%$ do grupo formado por entrevistados da alta administração das IES ainda acredita que a IC não é prática entre os concorrentes.

A confiabilidade, mensurada a partir da análise Alpha de Cronbach, foi satisfatória para todos os construtos que compõem o 'Modelo Conceitual: Ciclo de Produção de Inteligência Competitiva para IES', demonstrando alto nível de correlação entre as perguntas/respostas do formulário, conforme indicado na Tabela 1.

Tabela 1 - Medidas de confiabilidade do 20 nível de constructos utilizados no 'Ciclo de Produção de IC para IES', via equações estruturais

\begin{tabular}{l|c}
\hline \multicolumn{1}{c|}{ Constructos de $\mathbf{2}^{\mathbf{0}}$ nível } & Confiabilidade do constructo (CR) \\
\hline \hline Planejamento & 0,954 \\
\hline Reunião das Informações & 0,954 \\
\hline Processamento do Material Coletado & 0,939 \\
\hline Difusão de Inteligência para os usuários & 0,937 \\
\hline
\end{tabular}

Fonte: Dados da pesquisa.

Como mencionado anteriormente, a composição, a quantidade e a definição das dimensões e variáveis dos constructos foram especificadas a priori. Por isso, foi realizado um teste de correlação das variáveis estudadas e foram excluídas as que apresentaram baixa correlação com o grupo de variáveis (ex-funcionários da concorrência, 
Proposição e validação de um modelo de inteligência competitiva específico para instituições de ensino superior (ies) privadas
Cassiane Barbosa da Silva; Frederico Cesar Mafra Pereira; Rodrigo Baroni de Carvalho; Ricardo Vinícius Dias Jordão

amigos/conhecidos/familiares e Jogos de Guerra). As cargas fatoriais de cada variável observada são demonstradas conforme seu respectivo constructo (Tabela 2), sendo encontrada significância estatística em todas elas.

\section{Tabela 2 - Cargas fatoriais dos itens segundo dimensão e variável analisadas}

\begin{tabular}{|c|c|c|}
\hline Etapa (construto de $2^{\circ}$ nível) e Dimensão (construto de $1^{\circ}$ nível) & Item & $\begin{array}{l}\text { Carga } \\
\text { fatorial }\end{array}$ \\
\hline \multicolumn{3}{|l|}{ Etapa 1. Planejamento } \\
\hline \multicolumn{3}{|l|}{ Dimensão 1.1. Planejamento } \\
\hline Planejamento das atividades de coleta, processamento e distribuição das informações & Q14_1 & 0,894 \\
\hline Identificação dos usuários de informação na instituição & Q14_2 & 0,931 \\
\hline Mapeamento periódico das necessidades informacionais dos usuários da alta administração & Q14_3 & 0,862 \\
\hline Mapeamento periódico das necessidades informacionais dos usuários tomadores de decisão & Q14_4 & 0,942 \\
\hline Avaliação/mensuração dos resultados das atividades relacionadas a coleta de informações & Q14_5 & 0,973 \\
\hline \multicolumn{3}{|l|}{ Dimensão 1.2. Equipe de Inteligência: Profissional designado para a Gestão da Informação } \\
\hline Gestor & Q19_1 & 0,786 \\
\hline Analista & Q19_2 & 0,685 \\
\hline Coletores & Q19_3 & 0,679 \\
\hline \multicolumn{3}{|l|}{ Etapa 2. Reunião das informações } \\
\hline \multicolumn{3}{|l|}{ Dimensão 2.1. Ambiente Externo: Informações acompanhadas pela IES } \\
\hline Informações políticas, regulatórias e leis & Q15_1 & 0,871 \\
\hline Informações tecnológicas e inovações & Q15_2 & 0,905 \\
\hline Informações socioculturais e demográficas & Q15_3 & 0,909 \\
\hline Informações econômicas & Q15_4 & 0,935 \\
\hline Informações do meio ambiente & Q15_5 & 0,798 \\
\hline \multicolumn{3}{|l|}{ Dimensão 2.2. Fontes de Informação } \\
\hline Média de concordância das fontes de informações acompanhadas pela IES & Q16_m & 0,808 \\
\hline \multicolumn{3}{|l|}{ Dimensão 2.3. Métodos/Instrumentos de Coleta de Dados } \\
\hline Média de concordância dos métodos/instrumentos de coleta de dados e informações da IES & Q17_m & 0,801 \\
\hline \multicolumn{3}{|l|}{ Etapa 3. Processamento do Material Coletado } \\
\hline \multicolumn{3}{|l|}{ Dimensão 3.1. Ferramentas de Análise Setorial e do Ambiente } \\
\hline Análise de cadeia de valor & Q18_1 & 0,646 \\
\hline Benchmarking & Q18_2 & 0,699 \\
\hline Planejamento de cenários & Q18_3 & 0,824 \\
\hline Análise SWOT & Q18_4 & 0,624 \\
\hline Planejamento Estratégico & Q18_5 & 0,829 \\
\hline Forças de Porter & Q18_6 & 0,612 \\
\hline Fatores críticos de sucesso & Q18_7 & 0,757 \\
\hline \multicolumn{3}{|l|}{ Dimensão 3.2. Processamento de Dados } \\
\hline Presença e uso de software/ferramenta de processamento de dados interno & Q20_1 & 0,888 \\
\hline Presença e uso de softwares/ferramenta de processamento de dados externo & Q20_2 & 0,771 \\
\hline
\end{tabular}




\begin{tabular}{l|c|c}
\hline Presença e uso de técnicas e métodos adequados de tratamento e análise de dados & Q20_3 & 0,936 \\
\hline Presença e uso de apresentação adequada dos dados e informações & Q20_4 & 0,922 \\
\hline Etapa 4. Difusão da Inteligência para os usuários & Q21_1 & 0,691 \\
\hline Meio pelo qual recebo informações (e-mail, relatório impresso, portal institucional) & Q21_2 & 0,728 \\
\hline Formato dos produtos de informação (relatórios, releases, paper, pareceres, Excel, Word, PDF, & \\
\hline PowerPoint) & Q21_3 & 0,979 \\
\hline Dados e informações confiáveis & Q21_4 & 0,964 \\
\hline Dados e informações relevantes e pertinentes & Q21_5 & 0,832 \\
\hline Dados e informações tempestivas & Q21_6 & 0,844 \\
\hline Periodicidade de envio dos produtos de informação &
\end{tabular}

Fonte: Dados da pesquisa.

As medidas de ajuste do modelo são apresentadas na Tabela 3. A estatística CMIN/df apresentou resultado satisfatório. As demais medidas não resultaram em valores estabelecidos dentro do intervalo especificado, porém, apresentaram valores próximos. O principal aspecto que influenciou para que o modelo não tenha atendido a todas as especificações de ajuste foi o tamanho da amostra - 40 entrevistados. Devido à necessidade de se calcular muitos parâmetros (variáveis), uma amostra pequena pode trazer resultados que impactam nas estatísticas que verificam se o modelo se ajusta a uma população - não apenas a uma amostra - e também de análise de ajuste incremental. Contudo, levandose em consideração a amostra, o modelo apresentou bons resultados (FIG.6) sendo assim recomendada sua adoção em IES privadas em Minas Gerais.

Tabela 3 - Estatísticas de ajuste do modelo de equações estruturais

\begin{tabular}{c|c|c|c}
\hline $\begin{array}{c}\text { CMIN / df (qui- } \\
\text { quadrado / graus de } \\
\text { liberdade) }\end{array}$ & CFI (Comparative Fit Index) & IFI (Incremental Fit Index) & $\begin{array}{c}\text { RMSEA (Root Mean Square } \\
\text { Error of Approximation) }\end{array}$ \\
\hline \hline $\mathbf{2 , 3 3 5}$ & 0,689 & 0,696 & 0,147 \\
\hline
\end{tabular}

Fonte: Dados da pesquisa.

Figura 6 - Modelo de equações estruturais de Inteligência Competitiva 


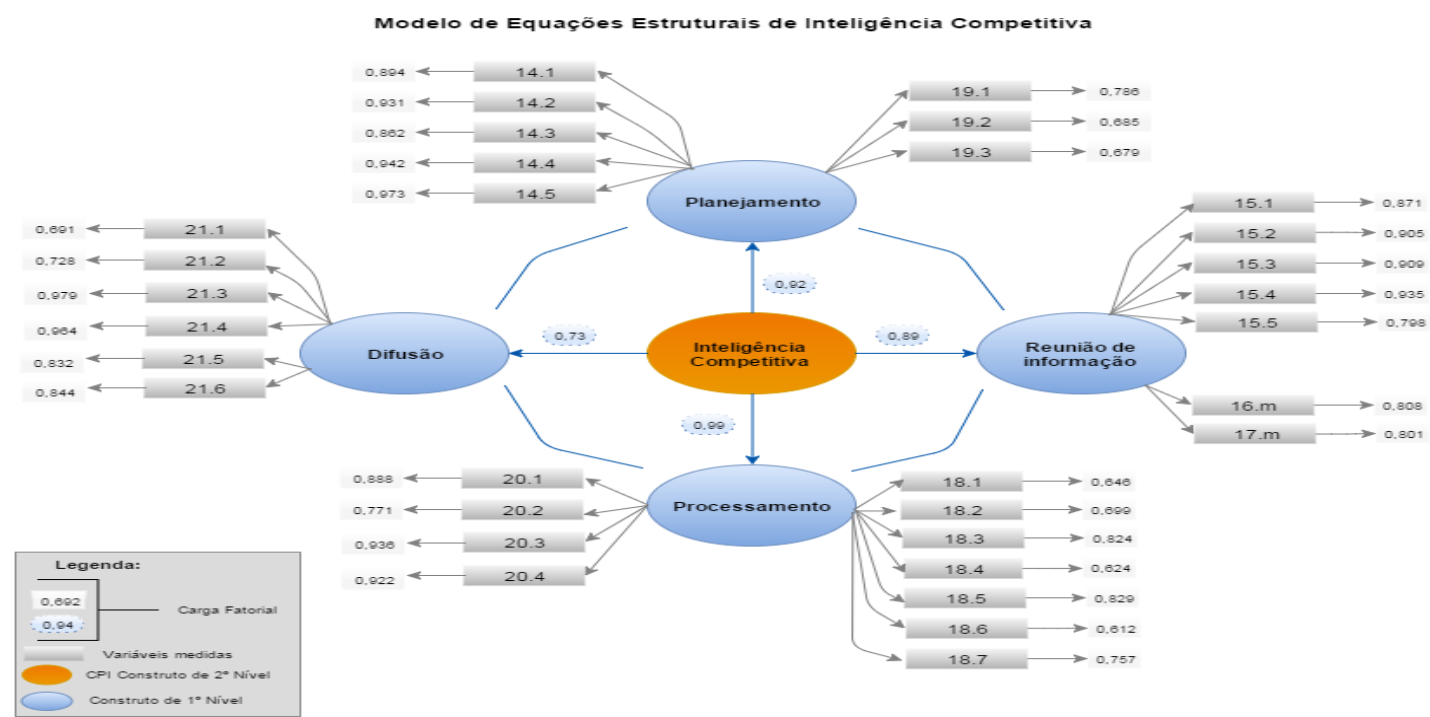

Fonte: Dados da pesquisa.

\section{Conclusões}

A delimitação teórica do trabalho foi realizada em torno do tema da IC. Assim, foi possível perceber uma diversidade considerável de metodologias e modelos de IC que vêm sendo adotados e aplicados pelas organizações em diferentes contextos organizacionais ou setores de atuação. Quanto às terminologias encontradas, também existe variedade de denominações e termos que apresentam conceitos e processos essencialmente parecidos com a finalidade de produção de inteligência para os negócios. Deste modo, infere-se que existem três diretivas para a IC. A primeira conduz para o planejamento e o enfoque da IC na organização, definindo em que frente atuar (se tática ou estratégica); a segunda demonstra que a atividade concentra diferentes ferramentas, práticas e análises da ambiência; e a terceira diz respeito à composição da equipe de profissionais que deve estar alinhada com o tipo de negócio e o foco de atuação da IC.

O setor de ensino superior privado de Minas Gerais compôs a unidade de análise desta pesquisa. As análises descritivas demonstraram diferenças perceptuais dos públicos abordados na pesquisa (alta administração e coordenação) frente à IC (conceitos e metodologias). Apesar dos dois grupos estudados apresentarem características sem diferenças significativas quanto à experiência na gestão e no cargo atual, os conceitos sobre IC parecem mais difundidos e as práticas mais implementadas nas IES mineiras na opinião dos gestores da alta administração do que para os gestores da coordenação.

Entretanto, percebe-se que as práticas e ferramentas de monitoramento estão presentes nas IES mineiras em um nível informal e desestruturado. A maioria das instituições pesquisadas não apresenta uma área específica para os processos ligados à IC; contudo, conceitualmente apresenta ótimo nível de conhecimento sobre o conceito, e mais de $80 \%$ dos entrevistados percebem vantagem e diferencial competitivo mais 
elevado com o uso de práticas e ferramentas de IC. Porém, destaca-se que, com relação à capacidade de previsão de eventos futuros por parte das IES, os participantes avaliaram-na como média, e apenas $31,4 \%$ dos entrevistados consideram as instituições às quais representam proativas, com visão de futuro e ações com base em estudos prospectivos.

A etapa de análises multivariadas permitiu a validação do modelo proposto ('Ciclo de Produção de Inteligência Competitiva para IES'). Os resultados demonstraram que os constructos de $2^{\circ}$ nível apresentam confiabilidade satisfatória segundo os parâmetros Alpha de Cronbach. Analisando as variáveis que compõem os construtos de $1^{0}$ nível, elencadas a priori, todas demonstraram significância estatística, sendo considerado como um bom modelo, recomendável à implantação em IES privadas.

Quanto ao público-alvo da pesquisa, foi possível levantar alguns pressupostos. O primeiro é de que existe maior integração da IC com a estratégia organizacional do que com a função tática. No mercado estudado, a figura do coordenador está muito mais ligada às funções acadêmicas e administrativas, quase operativas, o que nos leva a um segundo pressuposto de que os coordenadores não estão suficientemente envolvidos no planejamento estratégico das instituições que representam, ou seja, nesse mercado não é comum o envolvimento da coordenação de cursos no planejamento. O terceiro pressuposto é de que a alta administração tende a supervalorizar o nível de implementação das atividades organizacionais relacionadas ao planejamento estratégico. Ainda sobre os coordenadores e os resultados encontrados, destaca-se que, em instituições de ensino, é relativamente comum que professores assumam a função de gestores para a qual, nem sempre, apresentam as competências necessárias para um desempenho satisfatório.

Os resultados encontrados apontam que, para uma análise mais apurada quanto ao conhecimento e uso de IC em IES, dever-se-á abordar apenas um dos grupos aqui pesquisados - a alta administração -, uma vez que o grupo da coordenação pareceu não ser tão envolvido nos processos relacionados com o CPI e com o modelo analisado. Sendo assim, fica como sugestão para estudos futuros uma definição amostral específica com a alta administração de IES privadas. Além desta, recomenda-se a realização de uma pesquisa qualitativa com o grupo de IES participantes para que os pressupostos levantados possam ser explorados. Outra sugestão diz respeito à ampliação do estudo em termos geográficos, levando em consideração uma pesquisa em âmbito nacional para validação do modelo proposto. Recomenda-se, ainda, que sejam realizados estudos em outros setores de negócios que derivem na proposição de modelos mais específicos de IC.

Por fim, pode-se concluir que este trabalho possui potencial para contribuir não somente com a teoria sobre IC e com os campos da Ciência da Informação e da Administração, como também para as IES privadas, permitindo-as refletirem sobre suas práticas e o uso de ferramentas e métodos com vistas ao monitoramento de informações do ambiente 
externo, o suporte ao processo estratégico e a criação de vantagens competitivas para este tipo de organização. A utilização de modelos de IC direcionados a um determinado setor facilita a sua implementação, conforme seus conceitos gerais, e também ajuda na eficácia do próprio processo de inteligência, visto que seus designs, tanto em termos de estrutura, quanto de funcionamento, se mostram adequados à dinâmica e à realidade de negócios das empresas atuantes nesses setores.

\section{Referências}

BERNHARDT, D. Competitive intelligence: how to acquire and use corporate intelligence and counter-intelligence. London: Prentice Hall, 2004.

BOGERS, M; CHESBROUGH, H.; MOEDAS, C. Open innovation: research, practices, and policies. California Management Review, v. 60, n. 2, p. 5$16,2018$.

BRASIL. Ministério da Educação (MEC). Lei no 9.394, de 20 de dezembro de 1996. Estabelece as diretrizes e bases da educação nacional. DOU, Brasília, 23 dez. 1996.2 Disponível em: <http://www.planalto.gov.br/Ccivil_03/leis/L9394.htm>. Acesso em: 1 dez. 2015.

BRASIL. Ministério da Educação (MEC). Instituto Nacional de Estudos e Pesquisas Educacionais (INEP). Microdados Censo da Educação Superior. 2013. Disponível em: <http://portal.inep.gov.br/microdados >. Acesso em: 1 dez. 2015.

BRASIL. Ministério da Educação (MEC). e-MEC. Instiuições de curso superior e cursos cadastrados. 2015. Disponível em: <http://emec.mec.gov.br/>. Acesso em: 1 dez. 2015.

CANO-KOLLMANN, M. et al. Burying the hatchet for catch-up: open innovation among industry laggards in the automotive industry. California Management Review, v. 60, n. 2, p. 17-42, 2018.

CARDOSO JR., W. F. Inteligência empresarial estratégica: método e implantação de inteligência competitiva em organizações. Tubarão: Unisul, 2005.

CARVALHO, A. R. M.; CASAGRANDE, R. M. Instituições de ensino superior: um estudo sobre a adequação das gestões do conhecimento e da informação na busca de ferramentas para inteligência competitiva. In: COLÓQUIO INTERNACIONAL SOBRE GESTÃO UNIVERSITÁRIA NA AMÉRICA DO SUL, 9., Florianópolis, SC, Brasil, 2011. Anais... 2011. p. 112. Disponível

em: <http://repositorio.ufsc.br/xmlui/handle/123456789/44245>. Acesso em: 1 dez. 2015.

COLAUTO, D.R.; GONÇALVES, M.C.; MADEIRA, G.J. Matriz de inteligência competitiva para gestão estratégica, pedagógica e administrativa em 
universidades públicas. In: COLÓQUIO INTERNACIONAL SOBRE GESTÃO UNIVERSITÁRIA NA AMÉRICA DO SUL, 6., Florianópolis, SC, Brasil, 2006. Anais... 2006. p. 1-10. Disponível em: <http://repositorio.ufsc.br/xmlui/handle/123456789/66609 >. Acesso em 1 nov. 2015.

COLLIS, J.; HUSSEY, R. Pesquisa em administração: um guia prático para alunos de graduação e pós-graduação. 2. ed. Porto Alegre: Bookman, 2006.

FULD, L. M. Inteligência competitiva: como se manter à frente dos movimentos da concorrência e do mercado. Rio de Janeiro: Elsevier, 2007.

GOMES, E.; BRAGA, F. Inteligência competitiva: como transformar informação em um negócio lucrativo. 1. ed. Rio de Janeiro: Campus, 2001.

HAIR, J. F. et al. Análise multivariada de dados. 6. ed. Porto Alegre: Bookman, 2009.

HERRING, J.P. Key intelligence topics: a process to identify and define inteligence needs. Competitive Intelligence Review, v. 10, n. 2, p. 4-14, 1999.

HERRING, J. P. Tópicos fundamentais de inteligência: processo para identificação e definição de necessidades de inteligência. In: PRESCOTT, J. E.; MILLER, S. H. Inteligência competitiva na prática. Rio de Janeiro: Campus, 2002. p. 274-291.

JORDÃO, R. V. D.; NOVAS, J. C. A study on the use of the balanced scorecard for strategy implementation in a large Brazilian mixed economy company. Journal of Technology Management \& Innovation, v. 8, n. 3, p. 98-107, 2013.

JORDÃO, R. V. D.; SOUZA, A. A.; AVELAR, E. A. Organizational culture and post-acquisition changes in management control systems: an analysis of a successful Brazilian case. Journal of Business Research, v. 67, n. 4, p. 542-549, 2014.

LODI, C. F. G. Planejamento por cenários e inteligência competitiva: integrando seus processos para tomar decisões estratégicas mais eficazes. In: STAREC, C.; GOMES, E.; BEZERRA, J. (Orgs). Gestão estratégica da informação e inteligência competitiva. São Paulo: Saraiva, 2005. p. 124142.

MACEDO, D. L.; RODRIGUES, L. C. Sistema de inteligência acadêmica como suporte à formulação de estratégias na gestão da pós-graduação stricto sensu em Administração. 2012. Disponível em: <http://biblioteca.versila.com/2610528>. Acesso em: 12 nov. 2015.

MAFRA PEREIRA, F. C., BARBOSA, R. R. Uso de fontes de informação por consultores empresariais: um estudo junto ao mercado de consultoria de 
Belo Horizonte. Perspectivas em Ciência da Informação, Belo Horizonte, v. 13, p. 95-111, 2008.

MAFRA PEREIRA, F. C.; BORGES, M. A.; JORDÃO, R. V. D. Inteligência competitiva em redes interorganizacionais: proposta de modelo para centrais de negócios. In: ENCONTRO NACIONAL DE PESQUISA EM CIÊNCIA DA INFORMAÇÃO, 16., João Pessoa, PB, Brasil, 2015. Anais... 2015.

p. $\quad 1-12$.

Disponível

em: <http://www.ufpb.br/evento/lti/ocs/index.php/enancib2015/enancib2015/ paper/viewFile/2778/1081 >. Acesso em: 10 fev. 2016.

MAFRA PEREIRA, F. C.; SANTOS, M. G. A. Inteligência competitiva na indústria alimentícia: práticas adotadas e proposta de estruturação da IC em uma empresa de Processamento Mínimo de Frutas e Hortaliças de Minas Gerais. Revista Inteligência Competitiva, São Paulo, v. 5, n. 4, p. 128, 2015.

MAFRA PEREIRA, F. C.; CARVALHO, R. B.; JORDÃO, R. V. D. Análise do ciclo de inteligência em arranjos produtivos locais: estruturação e implantação do Bureau de Inteligência do APL de Software de Belo Horizonte. Revista Inteligência Competitiva, São Paulo, v. 6, n. 1, p. 139$164,2016$.

MAFRA PEREIRA, F. C. Fontes de informação para negócios: análise sobre frequência, relevância e confiabilidade, baseada em estudo empírico com empresários e gestores organizacionais. Perspectivas em Ciência da Informação, Belo Horizonte, v. 21, p. 100-119, 2016.

MALHOTRA, N.K. Pesquisa de marketing: uma orientação aplicada. 3. ed. Porto Alegre: Bookman, 2012.

MILLER, J. P. O milênio da inteligência competitiva. Porto Alegre: Bookman, 2002.

PORTER, M. E. Estratégia competitiva: técnicas para análise de indústrias e da concorrência. 7. ed. Rio de Janeiro: Campus, 1986.

PORTER, M.E. Vantagem competitiva: criando e sustentando um desempenho superior. 21. ed. Rio de Janeiro: Campus, 1989.

PRESCOTT, J. E.; MILLER, S. H. Inteligência competitiva na prática: técnicas e práticas bem-sucedidas para conquistar mercados. Rio de Janeiro: Campus, 2002.

RODRIGUES, L. C.; RICCARDI, R. Inteligência competitiva: nos negócios e organizações. Maringá: Unicorpe, 2007.

TARAPANOFF, K. (Org). Inteligência organizacional e competitiva. Brasília: Universidade de Brasília; IBICT; UNESCO, 2001.

TRIVIÑOS, A. N. S. Introdução à pesquisa em ciências sociais: a pesquisa qualitativa em educação. 3. ed. São Paulo: Atlas, 1992.

TYSON, K. W. M. Competitor intelligence manual and guide. Englewood Cliffs: Prentice Hall, 1990. 
Proposição e validação de um modelo de inteligência competitiva específico para instituições de ensino superior (ies) privadas
Cassiane Barbosa da Silva; Frederico Cesar Mafra Pereira; Rodrigo Baroni de Carvalho; Ricardo Vinícius Dias Jordão

VIDIGAL, F.; NASSIF, M. E. Inteligência Competitiva: metodologias aplicadas em empresas brasileiras. Informação \& Informação, Londrina, v. 17, n.1, p. 93-119, 2012. 